\title{
ONLINE INTERACTION IN SOCIAL LEARNING ENVIRONMENT TOWARDS CRITICAL THINKING SKILL: A FRAMEWORK
}

\author{
Wan Nur Tasnim Wan Hussin (D), Jamalludin Harun (D), Nurbiha A. Shukor (iD) \\ School of Education, Faculty of Social Sciences and Humanities, Universiti Teknologi Malaysia (Malaysia) \\ wntasnim2@live.utm.my,p-jamal@utm.my,nurbiha@utm.my
}

Received September 2018

Accepted December 2018

\begin{abstract}
Interaction is one of the crucial processes in online learning, which is a process derived from a common encouragement among people action that they able to utilize, store, share and construct knowledge. It is believed that the interaction among students is able to train the students to involve in active learning and enhance critical thinking skill. Recently, critical thinking is recognized as one of the 21 st-century skills that students must have to do well in the community. The engagement of the students in a learning environment that supports higher-order thinking activity is the most effective approach to guide the students in developing critical thinking skills. Nevertheless, without the assistance of technology, it may be nearly impossible to ensure that all students have access to learning environments that support and develop these skills. The way students study, interact and think has been shifted due to the increasing use of technologies in learning institutions, particularly during online learning. The online platform is better when there are students interact with each other in form of social learning. Nonetheless, limited research is available on how online interaction in the social learning environment can promote students' critical thinking skill. This study utilized a theory-building method to design the framework. The purpose of the framework of this study is to assist other practitioners and researchers in applying the elements of online interaction in a social learning environment to foster students' critical thinking skill.
\end{abstract}

Keywords - Critical thinking, Interaction, Online learning, Social learning environment, Framework.

\section{To cite this article:}

Hussin, W.N.T.W., Harun, J., \& Shukor, N.A. (2019). Online interaction in social learning environment towards critical thinking skill: A framework. Journal of Technology and Science Education, 9(1), 4-12. https://doi.org/10.3926/jotse.544

\section{Introduction}

The interaction among students is vital to ensure meaningful and deep learning (Azer, 2009). Interaction is action among people derived from the mutual influence which they can share, retrieve and store important knowledge (Din, Haron, Ahmad \& Rashid, 2015). "Social presence" of the students in an online learning environment is crucial to persuade students' active involvement and interaction in learning (Razzak, 2016). Online discussions offer students the opportunity to interact in responding to peers' and instructors' posts (Kent, Laslo \& Rafaeli, 2016). The students may excel better in academic achievement and may construct new knowledge (Kimber \& Wyatt-Smith, 2010) by utilising online learning, as the students understand 
better through active interactions in social learning. Apart from that, interaction via social learning is able to bridge the gap among students, teachers or lecturers in terms of communication (Al-Rahmi \& Zeki, 2017). Thus, interactions must be coherent among the peers as the discussion can proceed to online academic tasks such as research for relevant articles, discussion on assignments, and revisions (Din et al., 2015).

Nevertheless, despite all these advantages offered by "interaction", critical thinking does not seem to be popular in social environments (Razzak, 2016). Developing critical thinking skills of the student is regarded as an important educational goal in many societies around the world, as it can promote personal development (Larsson, 2017). For instance, tasks such as peers' reviews, discussions and knowledge construction motivate the students to continue learning and familiarity for next movement to improve critical thinking via online interaction (Heo, Lim \& Kim, 2010). Numerous opportunities and tools to assist interaction among students could be supplied for successful social learning (McLoughlin, 2002). The online interaction with instructors and peers offers advantages such as can get feedback from peers and instructors, and a prospect to study the exchanged messages (Alabdulkareem, 2015). The students can enhance critical thinking skills by expressing their opinions, challenging the ideas of others, discussing and collaborating each other for a solution to a provided problem (Brindley, Blaschke \& Walti, 2009). Razzak (2016) reported a number of researches that revealed there are efficient asynchronous tools i.e. threaded messages in discussion and tasks based on technologies being used for critical thinking enhancement. Thus, to obtain a more meaningful and engaging online discussions and tasks, there is a need to design carefully including having clear instructions, close monitoring and feedback from the instructors to foster critical thinking skills of the students (Hanna, Glowacki-Dudka \& Conceicao-Runlee, 2000; Horton, 2000; MacKnight, 2000). Therefore, the research question of this study is, "what are the elements of effective social learning online interaction that promotes critical thinking?" Hence, there is a need for a framework to improve critical thinking for effective online interaction in social learning.

\section{Literature Review}

\subsection{Social Constructivism Learning Theory and Online Interaction}

Based on the 'social constructivism' discovered by Vygotsky (1978), it recommended that knowledge occurs first within a social context. Furthermore, in his social constructivism theory, he explained that higher-order thinking is more likely to be produced via social interaction medium. One vital aspect of utilising social learning environment (SLE) is that it offers interaction between students, that indicates to better online socialisation (Raspopovic, Cvetanovic, Medan \& Ljubojevic, 2017). The students can involve in learning better at flexible time and place. Thus, active and meaningful learning can be promoted through online learning. In this research, SLE was used as an environment for online learning. The teacher or lecturer started the discussion with tasks, questions or problems to encourage students' interaction. The students might involve in the discussion by providing an answer, raising a question to ascertain a particular issue. Besides, the students were required to work in a group to solve problems which were posted on SLE. Based on the students' online post, the instructors may modify problems, tasks and other references to enrich students' prior knowledge level while maintaining students' interaction via online learning progression.

According to previous studies, interaction among students in the same group is able to attract the students during the learning process and can motivate each group member to engage in problem-solving together. Apart from that, the interaction factor among students during the learning process also plays an important role in improving critical thinking skills of the students as it encourages the students to solve the given problems actively (González-González \& Jiménez-Zarco, 2015; Newman, Johnson, Cochrane \& dan Webb, 1996). Therefore, such interaction should be emphasized in the teaching and learning process (Liu \& Tsai, 2008; Huber \& Huber, 2007; Land, Choi \& dan Ge, 2007). Chou, Peng and Chang (2010) stated that there are five types of learner online interaction in SLE which are learner-interface, learner-self, learner-content, learner-instructor and learner-learner. This study only focused on learner-learner interaction which learners can interact with each other by using SLE online medium. As this study only focused on learner-learner interaction in social learning, it adopted interaction analysis model from 
Gunawardena, Lowe and Anderson (1997). Many researchers recommended coding schemes for online discussion content analysis (Gunawardena et al., 1997; Chai \& Khine, 2006; Jeong, 2003). The following are the five coding schemes in interaction analysis model:

(i) Sharing and comparing of information (i.e. presenting new information to other members);

(ii) Discovery and exploration of dissonance or inconsistency among ideas, concepts or statements (i.e. answering and querying to clear the resource);

(iii) Negotiation of meaning/co-construction of knowledge (i.e. negotiating the meaning of terms);

(iv) Testing and modification of proposed synthesis (i.e. testing against personal experience) and,

(v) Agreement statement/applications of newly-constructed meaning (i.e. utilising and approving to the new idea).

Based on Google Scholar, Gunawardena et al. (1997) were cited in many papers. The study conducted by Yang, Li and Xing (2018) is one of the examples which adopted Gunawardena et al. (1997) coding scheme for the purpose of data coding to investigate the behavioural patterns of students' knowledge construction during online cooperative translation activities. Apart from that, a study conducted by Choo, Kaur, Fook and Yong (2014) also utilised Gunawardena et al. (1997) to determine the patterns of interaction demonstrated by English as a Second Language (ESL) groups during Online Collaboration.

Furthermore, this study added three effective interaction characteristics suggested by Johnson and Johnson (1996) to ensure meaningful and active interaction. The features are (i) response between the students with each other, (ii) exchange of resources among the students such as information and materials, and (iii) provision of assistance and guidance by the students.

\subsection{Online Interaction in Social Learning to Promote Critical Thinking}

Critical thinking includes the following elements: analysis, synthesis of new knowledge, evaluation of new concepts, prediction and capability to draw conclusions, self-regulation and decision making (Swart, 2017). The capability to generate decisions and derive conclusions can be improved through the development of critical thinking skills (Dwyer, Hogan \& Stewart, 2014). Various studies showed that the combination of social learning and interaction encourages the engagement of the students' in-depth thinking. Such combination is also beneficial in discussion and reflection to cultivate critical thinking (Swart, 2017). Critical thinking questions produce more questions for responder and questioner. Thus, such questions connect the students in thinking in their areas of study (McKnight in Khoshneshin, 2011). Mcknight suggested to promote critical thinking skills and motivate students in an online environment by using the prompts like Socratic questioning.

Besides that, critical thinking can be fostered through the interaction among students with each other as the students involved in active learning via discussion, argument and judgment-making. This study selected Facione Model (Facione, 1990) due to its focus on testing online thinking skills in a group interactive learning environment. This model suggests 6 skills which include:

(i) "Interpretation" which means categorization, decoding significance, and express a variety of events, experiences, beliefs, judgments, procedures and criteria;

(ii) "Analysis" which means probing ideas, identifying and analyzing arguments;

(iii) "Inference" which means finding elements needed to form hypotheses, making conclusions, pondering relevant information and deducing the consequences flowing from data, evidence, statements, beliefs, questions and speculating alternative.

(iv) "Evaluation" which means assessing the trustworthiness of statements which are descriptions of someone's experience, perception, judgment; and assessing the logical strength of the actual inferential relationships among statements or other forms of representation. 
(v) "Explanation" means affirming results, validating procedures and portraying arguments.

(vi) "Self-regulation" means self-correction and self-examination.

ŽivkoviL - (2016) is an example of a study which used Facionne (1990) for employing a critical thinking model and enhancing learning efficiency.

\section{Research Methods: Theory Building}

Dubin's theory-building method, Grounded theory building, Social constructionist theory building, Meta-analytic theory building and Theory building from case study research, are the five types of theory building method available (Torraco, 2002). Dubin's theory building is the Theory building used in this study. Such theory can be defined as a purposeful recurring cycle by representations and descriptions of experienced phenomena are generated, verified, and refined (Lynham, 2000). A five-phase method of theory-building was recommended by Lynham (2002) as a recursive system from Dubin's theory building. These include conceptual development, operationalization, confirmation or disconfirmation, application and continuous refinement and development. This method consists of two components: theorizing-to-practice and practice-to-theorizing. The theorising-to-practice was adopted as the research strategy due to its appropriateness to the behavioural and human sciences (Lynham, 2002) including education. There are 369 articles cited Lynham's theory building. This study noted that "A Framework for Interaction and Cognitive Engagement in Connectivist Learning Contexts" by Wang, Cheng and Anderson (2014) is the article that applied similar theory building methodology which stimulated both research and practice and resulted in later enhancements. This study analysed the interaction in social learning as a system, designing a framework to explain the elements of interaction in social learning to promote critical thinking.

\subsection{Conceptual Framework for Online Interaction in Social Learning to Promote Critical Thinking}

According to "social constructivism" stated by Vygotsky (1978), knowledge is first constructed in a social context. He emphasized that it will be more appropriate to create higher order thinking through the medium of social interaction in social learning theory. Figure 1 showed the relation of the previous statement.

There are many online medium of interaction and learning. Social learning theory stated that the interaction can occur among many types of learner. According to Chou et al. (2010), 5 types of online interaction are available. Nevertheless, this study only focused on learner-learner interaction. Among numerous higher orders thinking skills such as reflective thinking and creative thinking, this study focused on critical thinking skill. Figure 2 showed the relation of the previous statement.

The study showed that elements of interaction from Gunawardena et al. (1997) and Johnson and Johnson (1996) are reliable and supporting each other. Thus, this study adopted the elements from Gunawardena et al. (1997) with Johnson and Johnson (1996) to show there are effective online interactions in learner-learner interaction. Meanwhile, this study also used Facione model in 1990 for analysing the concept of critical thinking. Figure 3 below showed the basic framework of online interaction in social learning to promote critical thinking.

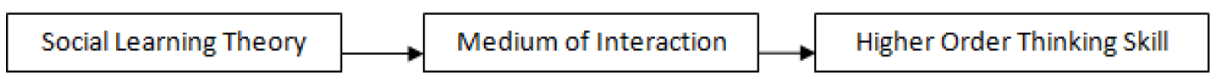

Figure 1. Basic flow from social learning theory to promote higher order thinking skill

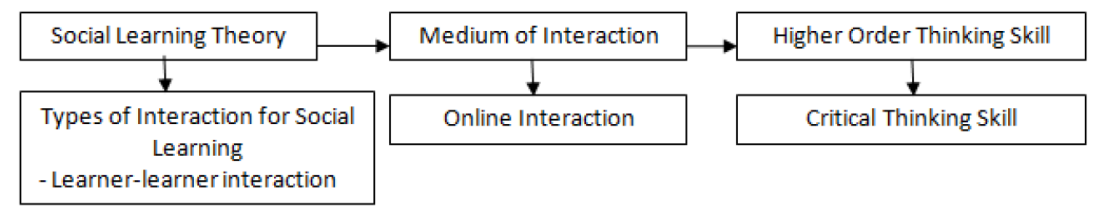

Figure 2. The revised of the figure from Figure 1 


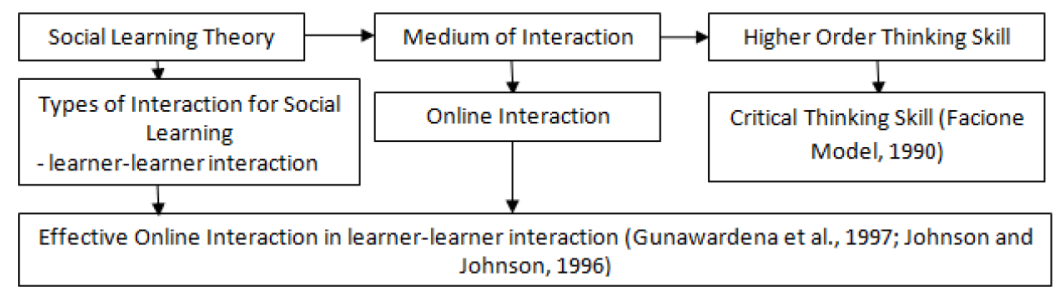

Figure 3. The basic framework of online interaction in social learning to promote critical thinking

\subsection{Conceptual Framework's Operationalization}

Theory-building research faced the challenge of creating the logic utilised to design the theory accessible to the user of the developed theory (Lynham, 2002). Based on a "Literature Review" subtopic and "Conceptual Framework for Online Interaction in Social Learning to Promote Critical Thinking" subtopic in this paper, the operationalized conceptual framework can be visualized as Figure 4. This is known as a framework for online interaction in a social learning environment to promote critical thinking. The purpose of this framework is to design a learning environment to motivate the critical thinking skills of the students. Online interaction in the social learning environment is able to support effective interaction among students. After learning and interacting, critical thinking skills of the students are being analysed based on Facione (1990).

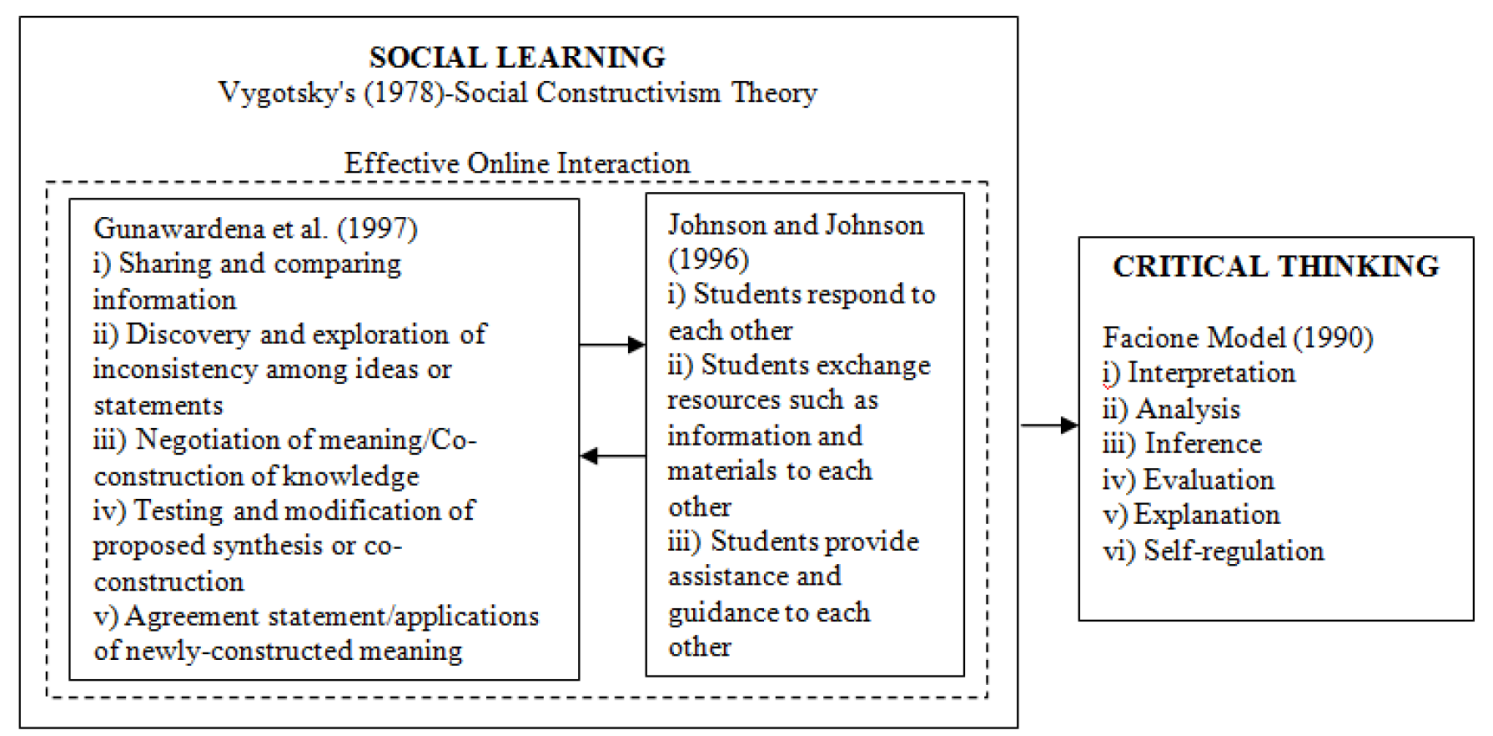

Figure 4. The framework of online interaction in social learning to promote critical thinking

\subsubsection{Interaction}

In this study, interaction analysis by Gunawardena et al. (1997) and Johnson and Johnson (1996) for effective online interaction in the social learning environment are chosen. Based on Figure 4 above, the effective online interaction occurred in 2 ways of direction. When the students responded to each other and exchanged resources, they also shared and compared information. Subsequently, they would discover and explore the inconsistency ideas and co-constructed the knowledge and vice versa. The students could have agreement statement and modification of proposed synthesis and vice versa when they provided assistance and guidance to each other.

\subsubsection{Social Learning}

Social learning is derived from Vygotsky's theory of social constructivism (1978). In this study, SLE was used as the environment for effective online interaction. SLE offers interaction among students, which 
leads to better online socialization (Raspopovic et al., 2017). Apart from that, SLE also enhances interaction among students in discussion and task/assignment/problem-sharing at anytime and anywhere.

\subsubsection{Critical Thinking}

In this study, students' critical thinking skill measured according to the elements from Facione Model (Facione, 1990). The study analysed the performance of the students after the effective online interaction in a social learning environment was conducted by the students. From the interaction analysis, this study evaluated the critical thinking skills of the students based on interpretation, analysis, inference, evaluation, explanation and self-regulation according to Facione Model (Facione, 1990).

\section{Discussion: The Interrelationship of Online Interaction, Social Learning and Critical Thinking}

Online interaction activities provided the students with a continuous learning experience and motivation towards advance improvement (Heo et al., 2010). The students learn through the interaction and exchange of critiques and ideas (Ali, Yaacob, Endut \& Langove, 2017). Many students acknowledged technology utilisation in improving their learning and assisting their growth of critical thinking (Swart, 2017). SLE appears as a method to enable interaction among students. The use of social learning inspires the students to participate and create comprehensive learning through interaction, critical thinking and collaboration (Liburd \& Christensen, 2013). Thus, SLE is designed as an ideal environment to improve interactions between the students and their instructors (Sobaih, Moustafa, Ghandforoush \& Khan, 2016). The education must focus on developing the critical thinking skills among students to ensure the students succeed in life. As a result, with critical thinking skill, the students are able to reflect critically and analytically, cooperate successfully, communicate effectively and resolve issues efficiently (ŽivkoviL, 2016). In other words, the students are required to be critical thinkers who are able to listen to the others' ideas, share their own ideas, summarise concepts by analysing, justifying, and preserving ideas, making decisions, and resolving real-life issues for global competitiveness. All the above require interactions among students in social learning to strengthen critical thinking skill. The variables (i.e. interaction, social learning and critical thinking) have different elements which require additional discovery.

The potential application that can be used from this proposed framework is learning activities design to encourage the students' interaction in social learning environment. This framework will act as the guideline and outline of students' criteria for an effective interaction. Besides that, from effective online interaction features that occur between the students in social learning environment, the students' critical thinking can be tested according to Facione Model (Facione, 1990). In other words, this proposed framework can be used to test the level of students' critical thinking skills with their style of interaction characteristics.

Nevertheless, currently, the whole framework is lack of validation. Despite so, it is believed that this framework diminishes the uncertainty and the manifold claims and aims related to social learning. Theory building is a systematic project which continues with expansion and improvement with its five phases. This paper only tackled the first and second phases as mentioned above. Thus, future research with the purpose of confirming this framework can focus on analysing the interaction process in social learning to improve critical thinking.

\section{Conclusion and Future Studies}

It is difficult to develop critical thinking without the interaction. Thus, online interaction through social learning is designed as the learning environment due to this factor. In this study, social learning is derived from Vygotsky's theory of social constructivism theory in 1978. To promote critical thinking skill framework, theory building method is adopted as a methodology to create the effective online interaction in social learning. For effective online interaction, this study also utilised the elements from Gunawardena et al. (1997) and Johnson and Johnson (1996) and, the elements of Facione Model (Facione, 1990) in 
terms of critical thinking evaluation. The framework of this study is able to assist the other practitioners to apply the elements of online interaction in a social learning environment to foster critical thinking skill of the students for purpose of redesigning teaching and learning. The framework can be tested for future work and also can be added with others learning approach.

\section{Declaration of Conflicting Interests}

The authors declared no potential conflicts of interest with respect to the research, authorship, and/or publication of this article.

\section{Funding}

The authors would like to thank the Universiti Teknologi Malaysia (UTM) and Ministry of Education (MoE) Malaysia for their support in making this project possible. This work was supported by the Research University Grant [Vote No: Q.J130000.2531.16H55] initiated by UTM and MoE.

\section{References}

Alabdulkareem, S.A. (2015). Exploring the use and the impacts of social media on teaching and learning science in Saudi. Procedia-Social and Behavioral Sciences, 182, 213-224.

https://doi.org/10.1016/j.sbspro.2015.04.758

Ali, M., Yaacob, R.A.I.B.R., Endut, M.N.A.A.B., \& Langove, N.U. (2017). Strengthening the academic usage of social media: An exploratory study. Journal of King Saud University-Computer and Information Sciences, 29(4), 553-561. https://doi.org/10.1016/j.jksuci.2016.10.002

Al-Rahmi, W.M., \& Zeki, A.M. (2017). A model of using social media for collaborative learning to enhance learners' performance on learning. Journal of King Saud University-Computer and Information Sciences, 29(4), 526-535. https://doi.org/10.1016/j.jksuci.2016.09.002

Azer, S.A. (2009). Interactions between students and tutor in problem-based learning: The significance of deep learning. The Kaobsiung journal of medical sciences, 25(5), 240-249. https://doi.org/10.1016/S1607551X(09)70068-3

Brindley, J., Blaschke, L.M., \& Walti, C. (2009). Creating effective collaborative learning groups in an online environment. The International Review of Research in Open and Distributed Learning, 10(3). https://doi.org/10.19173/irrodl.v10i3.675

Chai, C.S., \& Khine, M.S. (2006). An analysis of interaction and participation patterns in online community. Educational Technology \& Society, 9(1), 250-261.

Choo, L.P., Kaur, G., Fook, C.Y., \& Yong, T.C. (2014). Patterns of interaction among ESL students during online collaboration. Procedia-Social and Behavioral Sciences, 123, 307-314.

https://doi.org/10.1016/j.sbspro.2014.01.1428

Chou, C., Peng, H., \& Chang, C.Y. (2010). The technical framework of interactive functions for course-management systems: Students' perceptions, uses, and evaluations. Computers \& Education, 55(3), 1004-1017. https://doi.org/10.1016/j.compedu.2010.04.011

Din, N., Haron, S., Ahmad, H., \& Rashid, R.M. (2015). Technology Supported Cities and Effective Online Interaction for Learning. Procedia-Social and Behavioral Sciences, 170, 206-214. https://doi.org/10.1016/j.sbspro.2015.01.030

Dwyer, C.P., Hogan, M.J., \& Stewart, I. (2014). An integrated critical thinking framework for the 21st century. Thinking Skills and Creativity, 12, 43-52. https://doi.org/10.1016/j.tsc.2013.12.004

Facione, P.A. (1990). Critical thinking: A statement of expert consensus for purposes of educational assessment and instruction - The Delphi Report. Berkeley, CA: California Academic Press. 
González-González, I., \& Jiménez-Zarco, A.I. (2015). Using Learning Methodologies and Resources in the Development of Critical Thinking Competency: An Exploratory Study in a Virtual Learning Environment. Computers in Human Behavior. https://doi.org/10.1016/j.chb.2014.11.002 (Accessed: December 2017).

Gunawardena, C.N., Lowe, C.A., \& Anderson, T. (1997). Analysis of global online debate and the development of an interaction analysis model for examining social construction of knowledge in computer conferencing. Journal of Educational Computing Research, 17(4), 397-431.

https://doi.org/10.2190/7MQV-X9UJ-C7Q3-NRAG

Hanna, D.E., Glowacki-Dudka, M., \& Conceicao-Runlee, S. (2000). 147 practical tips for teaching online groups: essentials of web-based education. Madison: Atwood Publishing.

Heo, H., Lim, K.Y., \& Kim, Y. (2010). Exploratory study on the patterns of online interaction and knowledge co-construction in project-based learning. Computers \& Education, 55(3), 1383-1392. https://doi.org/10.1016/j.compedu.2010.06.012

Horton, S. (2000). Web Teacbing Guide: A Practical Approach to Creating Course Web Sites. New Haven and London: Yale University Press.

Huber, G.L., \& Huber, A.A. (2008). Structuring Group Interaction to Promote Thinking and Learning during Small Group Learning in High School Settings. In Gillies R.M., Ashman A.F., \& Terwel J. (Eds.), The Teacher's Role in Implementing Cooperative Learning in the Classroom (110-131). Springer US. https://doi.org/10.1007/978-0-387-70892-8_6

Jeong, A.C. (2003). The sequential analysis of grout interaction and critical thinking in online threaded discussions. The American Journal of Distance Education, 17(1), 25-43.

https://doi.org/10.1207/S15389286AJDE1701_3

Johnson, D.W., \& Johnson, R.T. (1996). Cooperation and the Use of Technology. Handbook of Research for Educational Communications and Technology: A Project of the Association for Educational Communications and Technology, 1017-1044.

Kent, C., Laslo, E., \& Rafaeli, S. (2016). Interactivity in online discussions and learning outcomes. Computers \& Education, 97, 116-128. https://doi.org/10.1016/j.compedu.2016.03.002

Khoshneshin, Z. (2011). Collaborative critical thinking in online environment. Procedia-Social and Behavioral Sciences, 30, 1881-1887. https://doi.org/10.1016/j.sbspro.2011.10.366

Kimber, K., \& Wyatt-Smith, C. (2010). Secondary students' online use and creation of knowledge:

Refocusing priorities for quality assessment and learning. Australasian journal of educational technology, 26(5). https://doi.org/10.14742/ajet.1054

Land, S.M., Choi, I., \& dan Ge, X. (2007). Scaffolding Online Discussions to Promote Reflection and Revision of Understanding. International Journal of Instructional Media, 34(4), 409.

Larsson, K. (2017). Understanding and teaching critical thinking - A new approach. International Journal of Educational Research, 84, 32-42. https://doi.org/10.1016/j.ijer.2017.05.004

Liburd, J.J., \& Christensen, I.M.F. (2013). Using web 2.0 in higher tourism education. Journal of Hospitality, Leisure, Sport \& Tourism Education, 12(1), 99-108. https://doi.org/10.1016/j.jhlste.2012.09.002

Liu, C., \& Tsai, C. (2008). An Analysis of Peer Interaction Patterns as Discoursed by On-line Small Group Problem-solving Activity. Computers \& Education, 50(3), 627-639.

https://doi.org/10.1016/j.compedu.2006.07.002

Lynham, S.A. (2000). The development of a theory of responsible leadership for performance (Tech. Rep.). St. Paul: University of Minnesota, Human Resource Development Research Center. 
Lynham, S.A. (2002). The general method of theory-building research in applied disciplines. Advances in Developing Human Resources, 4(3), 221-241. https://doi.org/10.1177/1523422302043002

MacKnight, C.B. (2000). Teaching critical thinking through online discussions. Educause Quarterly, 4, 38-41.

McLoughlin, C. (2002). Computer supported teamwork: An integrative approach to evaluating cooperative learning in an online environment. Australasian Journal of Educational Technology, 18(2). https://doi.org/10.14742/ajet.1757

Newman, D.R., Johnson, C., Cochrane, C., \& dan Webb, B. (1996). An Experiment in Group Learning Technology: Evaluating Critical Thinking in Face-to-face and Computer-supported Seminars. Interpersonal Computing and Technology Journal, 4(1), 57-74. Available at: http://www.qub.ac.uk/mgt/papers/ccvsem/contents.html

Raspopovic, M., Cvetanovic, S., Medan, I., \& Ljubojevic, D. (2017). The Effects of integrating Social Learning Environment with online learning. The International Review of Research in Open and Distributed Learning, 18(1). https://doi.org/10.19173/irrodl.v18i1.2645

Razzak, N.A. (2016). Strategies for effective faculty involvement in online activities aimed at promoting critical thinking and deep learning. Education and Information Technologies, 21(4), 881-896.

https://doi.org/10.1007/s10639-014-9359-z

Sobaih, A.E.E., Moustafa, M.A., Ghandforoush, P., \& Khan, M. (2016). To use or not to use? Social media in higher education in developing countries. Computers in Human Behavior, 58, 296-305.

https://doi.org/10.1016/j.chb.2016.01.002

Swart, R. (2017). Critical thinking instruction and technology enhanced learning from the student perspective: A mixed methods research study. Nurse education in practice, 23, 30-39.

https://doi.org/10.1016/j.nepr.2017.02.003

Torraco, R.J. (2002). Research methods for theory building in applied disciplines: A comparative analysis. Advances in Developing Human Resources, 4(3), 355-376. https://doi.org/10.1177/1523422302043008

Wang, Z., Chen, L., \& Anderson, T. (2014). A framework for interaction and cognitive engagement in connectivist learning contexts. The International Review of Research in Open and Distributed Learning, 15(2). https://doi.org/10.19173/irrodl.v15i2.1709

Vygotsky, L.S. (1978). Mind in society: The development of higher psychological process. Harvard University Pres.

Yang, X., Li, J., \& Xing, B. (2018). Behavioral patterns of knowledge construction in online cooperative translation activities. The Internet and Higher Education, 36, 13-21.

https://doi.org/10.1016/j.iheduc.2017.08.003

ŽivkoviL, S. (2016). A Model of Critical Thinking as an Important Attribute for Success in the 21st Century. Procedia-Social and Behavioral Sciences, 232, 102-108. https://doi.org/10.1016/j.sbspro.2016.10.034

Published by OmniaScience (www.omniascience.com)

Journal of Technology and Science Education, 2019 (www.jotse.org)

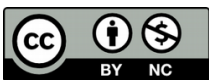

Article's contents are provided on an Attribution-Non Commercial 4.0 Creative commons International License. Readers are allowed to copy, distribute and communicate article's contents, provided the author's and JOTSE journal's names are included. It must not be used for commercial purposes. To see the complete licence contents, please visit https://creativecommons.org/licenses/by-nc/4.0/. 